\title{
Reflexões sobre o Uso de Documentos de Patentes em Cursos de Graduação*
}

\author{
Maria Cristina Comunian Ferraz
}

Departamento de Ciência da Informação - Universidade Federal de São Carlos

\section{Resumo}

O presente artigo tem como objetivo principal apresentar considerações sobre o uso da informação patentária por alunos de graduação. Apresenta, como exemplo de inclusão do tema no âmbito acadêmico, a Atividade Curricular de Integração entre Ensino, Pesquisa e Extensão desenvolvida na Universidade Federal de São Carlos, com foco na recuperação e uso da informação patentária no Brasil. O emprego de informaçôes contidas em documentos de patentes nas diversas atividades dos cursos de graduação é recomendado como forma de incentivar a utilização dessa importante fonte de informação tecnológica.

Palavras-Chave | Patentes; Informação Tecnológica; Informação para Negócios; Recuperação da Informação; Letramento em Ciência e Tecnologia

Códigos JEL | O34; I23

\footnotetext{
* Gostaria de agradecer ao professor doutor Leandro Innocentini Lopes de Faria, do Departamento de Ciência da Informação da UFSCar, e ao professor doutor Heitor Cury Basso, do Departamento de Engenharia Elétrica da USP, pelas contribuições a este trabalho. Agradeço também aos pareceristas da Revista Brasileira de Inovação, que, com a experiência e o conhecimento na área, contribuíram para o enriquecimento deste artigo, e à Pró-Reitoria de Graduação, Pró-Reitoria de Extensão e Pró-Reitoria de Pós-Graduação e Pesquisa da UFSCar pelo incentivo e apoio financeiro a este projeto.
} 
Abstract

The main aim of this article is to present considerations regarding the use of patent information by undergraduate students. As an example of inclusion of this theme in the academic field, it presents the Curricular Activity of Integration between Teaching, Research and Outside Activities with the community developed at the Federal University of São Carlos, focusing on the retrieval and use of patent information in Brazil. The use of information contained in patent documents in the various activities of the undergraduate courses is recommended as a way of stimulating the use of this important source of technological information.

KEYwORds I Patents; Technological Information; Information for Business; Information Retrieval; Science and Technology Literacy

JEL-CODES | O34; I23

\section{Introdução}

Quando se lê nos jornais matérias relacionadas à quebra de patentes de remédios contra a aids, pirataria em software no Brasil ou venda de produtos desenvolvimentos através do uso de conhecimento tradicional associado ao patrimônio genético, é de se perguntar se o cidadão/leitor possui conhecimentos mínimos sobre os direitos relativos à proteção do trabalho intelectual para entender o significado dessas notícias e se tem condiçôes de fazer uso desse conhecimento em suas práticas sociais.

Diversos fatores justificam a preocupação com a capacitação de recursos humanos em Propriedade Intelectual no Brasil: um cidadão letrado ${ }^{1}$

1 Para Santos (2006, p.613), uma pessoa letrada tecnologicamente "[...] teria o poder e a liberdade de usar seus conhecimentos para examinar e questionar os temas de importância na sociotecnologia. Isso implica ser crítico no uso da tecnologia, ou seja, ter a habilidade intelectual de examinar os prós e contras de algum desenvolvimento tecnológico, examinar o potencial de seus benefícios e de seus custos e perceber o que está por trás das forças políticas e sociais que orientam esse desenvolvimento. Isso vai além do conhecimento técnico específico sobre o uso da tecnologia que também se torna importante no mundo atual dominado por tantos aparatos tecnológicos". 
em Propriedade Intelectual tem condições de avaliar os fatos e as decisões políticas que embasam as ações noticiadas pelos veículos de comunicação de massa que tratam de temas relacionados ao assunto; é capaz de adotar uma postura ativa diante das discussões que permeiam os debates nacionais sobre temas relacionados à propriedade do trabalho intelectual; tem condições de participar da construção de políticas públicas em ciência e tecnologia, dentre outros fatores.

Das instituições que se dedicam à capacitação nessa área, grande destaque deve ser dado ao Instituto Nacional da Propriedade Industrial (INPI), que vem desenvolvendo diversas ações voltadas à promoção de um maior entendimento sobre o sistema de Propriedade Intelectual brasileiro (INPI, 2007). Entretanto, o ensino desse tema nas universidades brasileiras desperta preocupação: o resultado de um estudo realizado por Santos e Rossi, apresentado em 2002, mostra que a disciplina de Propriedade Intelectual era oferecida somente em 12 universidades das 26 pesquisadas que possuíam Núcleos de Propriedade Intelectual e Transferência de Tecnologia. Essas disciplinas geralmente eram ligadas a cursos de direito, e, na maioria das vezes, não se constituindo em disciplinas específicas: os conhecimentos sobre esse assunto integravam o conteúdo de outras disciplinas (Santos \& Rossi, 2002).

O presente artigo trata dos resultados de uma das fases de um projeto de pesquisa desenvolvido na Universidade Federal de São Carlos (UFSCar) denominado Letramento em Propriedade Intelectual e Conhecimento Tradicional, sob a responsabilidade da autora deste trabalho. Esse projeto possui duas vertentes que são conduzidas de forma independente e interligadas ao mesmo tempo:

a) a primeira se dedica ao aprofundamento teórico sobre temas relacionados à proteção do trabalho intelectual;

b) a segunda centra-se na concepção de Programas de Intervenção para o letramento científico e tecnológico em Propriedade Intelectual, dirigidos a alunos de graduação de instituições públicas de ensino superior.

A primeira fase desse projeto, que tem neste artigo alguns de seus resultados, teve como objetivos: 
a) a escolha e avaliação de metodologia adequada para o trabalho com temas relacionados à proteção do trabalho intelectual, em grupos multidisciplinares, com o propósito de gerar subsídios para a formulação de hipóteses, objetivos e indicadores de avaliação, que fundamentarão a construção e melhoria de programas de intervenção voltados a alunos de graduação;

b) a divulgação dos principais resultados obtidos com relação às primeiras práticas desenvolvidas.

O presente artigo, portanto, tem como foco principal o estudo, sob a ótica da Ciência da Informação, dos problemas relacionados à recuperação e uso da informação patentária por alunos de graduação. Teve como base a concepção de disciplinas especiais de graduação denominadas ACIEPE (Atividade Curricular de Integração Ensino, Pesquisa e Extensão), as primeiras disciplinas ACIEPE que trataram do tema patentes oferecidas pela UFSCar. Nessas disciplinas, coordenadas pela autora deste trabalho, foram utilizados recursos metodológicos diferenciados, destacando-se o uso das Tecnologias de Informação e Comunicação aliadas ao emprego de atividades lúdicas para auxiliar o processo ensino-aprendizagem.

A seguir será apresentado um breve resumo dos conceitos importantes utilizados no desenvolvimento das disciplinas, além de uma breve discussão sobre o tema central: a recuperação da informação. $\mathrm{Na}$ seqüência, serão descritos: as características das disciplinas (público-alvo, objetivos, conteúdo programático, recursos utilizados, critérios de avaliação); os resultados obtidos (grau de satisfação do aluno com relação à temática apresentada e à metodologia utilizada), analisados através da aplicação de um questionário contendo perguntas fechadas e abertas; as ações previstas para a continuidade do projeto de pesquisa Letramento em Propriedade Intelectual e Conhecimento Tradicional e as limitações referentes ao universo estudado e aos procedimentos de pesquisa adotados.

Pretende-se com este trabalho contribuir para a formação acadêmica e para o sucesso profissional dos alunos de graduação de instituições públicas de ensino superior. 


\section{Contribuições da Ciência da Informação para o uso da informação patentária}

Para um melhor entendimento das dificuldades encontradas na capacitação de recursos humanos para a recuperação da informação patentária, alguns conceitos, advindos da Ciência da Informação, serão apresentados. Não se pretende com isso fazer uma revisão da literatura ou esgotar o assunto, mas sim motivar o leitor a buscar, na Ciência da Informação, uma parceira para a solução de vários dos problemas relacionados à recuperação desse tipo de informação.

O presente artigo adotará a definição de Le Coadic (1996:5) para o conceito de informação, como "um conhecimento inscrito (gravado) sob a forma escrita (impressa ou numérica), oral ou audiovisual”. É um ativo que não se deteriora, é reutilizável, sendo seu valor determinado exclusivamente pelo usuário (McGee \& Prusak, 1994:23). A necessidade de informação de um usuário, portanto, é específica dele, não de outro e muito menos é ditada pelos serviços de informação que as suportam. Citando Kuhlthau (apud Furnival, 2002:6):

"Uma busca de informação começa com o problema do usuário. A lacuna (gap) entre o conhecimento que o usuário detém sobre o problema ou tópico e o que o usuário precisa saber para resolver o problema constitui a necessidade de informação".

Por serviço, entende-se tanto o produto de uma atividade humana que satisfaz a necessidade de um cliente, sem assumir a forma de um bem material (Prazeres, 1996:370), como as organizações que os executam. São chamados de serviços, por exemplo, os "serviços de informação, que são organizações sociais responsáveis pelo armazenamento, tratamento e disseminação de informaçôes" (Dias \& Ferraz, 2006:31).

A Ciência da Informação, área do conhecimento que se preocupa com os processos de coleta, organização, tratamento e disseminação da informação, pode auxiliar profissionais de diversas áreas a utilizar adequadamente os serviços de informação disponíveis. Na visão de Le Coadic (1996:26): 
"De prática de organização, a ciência da informação tornou-se, portanto, uma ciência social rigorosa que se apóia em uma tecnologia também rigorosa. Tem por objeto o estudo das propriedades gerais da informação (natureza, gênese, efeitos), ou seja, mais precisamente: a análise dos processos de construção, comunicação e uso da informação; e a concepção dos produtos e sistemas que permitem sua construção, comunicação, armazenamento e uso".

Diante das dificuldades encontradas em se chegar a um consenso terminológico sobre a tipologia da informação, refletindo-se na dificuldade de se trabalhar a informação do ponto de vista de seu valor econômico-social (Cysne, 1996:28), tornam-se assim oportunas as definiçōes utilizadas pelo presente trabalho.

Informação tecnológica é todo tipo de informação relacionada com o modo de fazer um produto, a forma de realizar um processo ou prestar um serviço, com o objetivo de colocá-lo no mercado, servindo para:

"[...] constituir insumo para o desenvolvimento de pesquisas tecnológicas; assegurar o direito de propriedade industrial para uma tecnologia nova que tenha sido desenvolvida; difundir tecnologias de dominio público para possibilitar a melhoria da qualidade e da produtividade de empreendimentos existentes; subsidiar o processo de gestão tecnológica; possibilitar o acompanhamento e a avaliação de tendências de desenvolvimento tecnológico; permitir a avaliação do impacto econômico, social e ambiental das tecnologias”. (Aguiar, 1991:11)

Já informação para negócios é a informação sobre companhias, produtos, finanças, estatísticas, legislação e mercado, utilizada para subsidiar o processo decisório do gerenciamento das empresas industriais, de prestação de serviços e comerciais (Montalli \& Campello, 1997:321).

Utilizar adequadamente tanto a informação tecnológica como a informação para negócios contidas nos documentos de patente é essencial em qualquer atividade de Pesquisa e Desenvolvimento ( $P \& D)$, tanto em instituições públicas como em instituições privadas. Segundo Allen (apud Aguiar, 1991:9): 
"[...] as atividades de desenvolvimento tecnológico necessitam de informaçôes, inicialmente para que o problema a ser enfrentado possa ser entendido e, depois, para indicar possiveis soluçôes - inclusive esclarecendo as conseqüencias de cada alternativa - para a abordagem do problema proposto".

Basicamente, qualquer sistema de recuperação de informação $o^{2}-$ um dos assuntos que merece maior destaque na formação de profissionais e nas pesquisas em Ciência da Informação - pode ser compreendido como formado por três etapas (Rowley, 2002:162): a indexação, o armazenamento e a recuperação. Diante das necessidades cada vez mais diversificadas de recuperação de informação, os sistemas de indexação tornaram-se mais complexos, para melhor representar o conteúdo dos documentos (Souza, 2000:2) e facilitar a recuperação deles. Para Furnival, dado um conjunto de documentos indexados, as necessidades dos usuários é que ditam qual documento deve ser recuperado:

"Dado um corpo de documentos indexados e uma população de usuários que, em momentos especificos, estarão buscando as informações contidas nos documentos para satisfazer suas necessidades de informação, pode-se presumir que haverá documentos que podem ser considerados 'relevantes' ou 'não-relevantes' àquelas necessidades informacionais dos usuários, e que somente aqueles documentos cujo conteúdo de informação inclua aquele da necessidade de informação devem ser recuperados". (2002:7)

Muitas bases de dados de patentes estão disponibilizadas para pesquisa na Internet e a recuperação da informação contida nesses documentos tem suas peculiaridades, que a difere da recuperação de outros tipos de informação. Projetada na década de 1960, a Internet permitiu o compartilhamento de dados e criou um sistema de comunicação único e descentralizado. Nos anos 1990, tornou-se comercial e amplamente difundida, sendo utilizada para comunicação pessoal, transações comerciais, troca de arquivos eletrônicos para a recuperação da informação, dentre outras funções (Brandão, 2003:91). Hoje

2 Para mais informações sobre esse assunto, pode-se recorrer a Lopes (2002a, 2002b); Boccato e Fujita (2006); Kaback, (1992); Furnival (2002); Ferneda (2003); Souza (2000); Branski (2004), dentre outros autores. 
se acessa rapidamente um conjunto cada vez maior de dados e informações, disponibilizados em diversas páginas que tratam dos mais variados assuntos.

Uma vez decidido o termo a ser usado na busca da informação, inerente ao diagnóstico da demanda do usuário, a definição da estratégia de busca (os campos a serem utilizados, o uso ou não de operadores booleanos etc.) é o passo seguinte (Pinho, Basso \& Ferraz, 2005:256). Entende-se por estratégia de busca uma técnica ou conjunto de regras para se obter a informação desejada, armazenada em uma base de dados (Lopes, 2002a:41). Só será eficiente se as informações recuperadas atenderem às necessidades do usuário, e essa eficiência está diretamente ligada ao conhecimento do usuário sobre o assunto e ao conhecimento do profissional responsável pela recuperação da informação sobre a estrutura da base de dados, dentre outros fatores (Gracioso, 2000:4).

Por buscadores, ferramentas de busca ou mecanismos de busca entendemse os sistemas utilizados na recuperação de informações. Branski (2004:71) menciona a importância do uso eficiente dessas ferramentas para se encontrar a informação desejada:

"Encontrar a informação depende, principalmente, do uso eficiente das ferramentas de busca. Para explorar todo o potencial dos buscadores, o usuário precisa conhecer: como é coletada e estruturada a informação em diferentes bancos de dados; suas características e limitaçôes; todas as possiveis formas de interação e suas linguagens de busca. Conceitua-se estrutura da informação como a sua organização lógica para posterior recuperação e linguagem de busca como os comandos que permitem a recuperação da informação através de palavras contidas nos títulos, resumos ou outros campos de dados".

$\mathrm{Na}$ base BRASPAT do INPI, que possui todos os pedidos de patentes e desenho industrial publicados no Brasil, desde 1992, com mais de 50 mil registros com dados bibliográficos e resumo dos pedidos publicados, pode-se recuperar a informação utilizando-se: o número do processo administrativo, palavras contidas em campos disponíveis para busca (título, resumo, nome do depositante, nome do inventor), a data de depósito, o número da prioridade, a data da prioridade, o país da prioridade, a Classificação Internacional de Patentes (CIP), dentre outros campos. 
Nos dias de hoje, todo jovem que possui computador com acesso à Internet traça as suas estratégias de recuperação da informação. Mas essas estratégias, determinadas empiricamente, sem conhecimento prévio dos sistemas e das características das próprias bases de dados consultadas, levam freqüentemente à informação desnecessária e até à informação não-confiável. No caso das patentes, a precisão na recuperação da informação é extremamente importante, pois não recuperar um documento pode levar empresas a investimentos em atividades de $\mathrm{P} \& \mathrm{D}$ relacionadas a tecnologias já existentes ou até mesmo à comercialização de produtos protegidos, desrespeitando os direitos de Propriedade Industrial. Portanto, a recuperação da informação, utilizando-se dos conhecimentos advindos da Ciência da Informação, que tem como foco atender às necessidades específicas de cada usuário, resulta em benefícios evidentes.

\section{A Atividade Curricular de Integração entre Ensino, Pesquisa e Extensão - ACIEPE}

As informaçôes contidas nas bases de patentes podem ser utilizadas por toda a sociedade, respeitando-se os direitos de propriedade intelectual, mesmo durante o prazo de vigência da patente. Desse tema tratam diversos autores (Ferraz, 2006; Cunha, 2001; Macedo \& Barbosa, 2000; Barbosa, 1999; Rodrigues, 1998; França, 1997; Strenger, 1996; Wandscheer, 2004; Antunes et al., 2000; Haase et al., 2005). De acordo com a Organização Mundial de Propriedade Industrial (OMPI), mais de $70 \%$ da informação tecnológica disponível somente pode ser encontrada nos documentos de patentes (Macedo \& Barbosa, 2000:57). Avaliar tendências de mercado, acompanhar o desenvolvimento tecnológico, monitorar a concorrência, obter informações e dados técnicos para o desenvolvimento de novos processos e produtos são alguns exemplos do emprego da informação contida nesses documentos citado em importante pesquisa publicada em 2003 pela Federação e pelo Centro das Indústrias do Estado de São Paulo - FIESP-CIESP (FIESP, 2003).

Dentre as ações voltadas à discussão de tão importante tema promovidas pelo Grupo de Pesquisa da UFS Car, denominado Informação, Conhecimento e Tecnologia, cadastrado no Diretório dos Grupos de Pesquisa do Conselho Nacional de Desenvolvimento Científico e Tecnológico (CNPq) desde 2002, 
tem-se a Atividade Curricular de Integração entre Ensino, Pesquisa e Extensão (ACIEPE), que trata da recuperação e uso da informação patentária por alunos de graduação.

As ACIEPE, foram implantadas na UFSCar em 2002, por meio de um projeto que envolveu as Pró-Reitorias de Graduação, Pós-Graduação e Pesquisa e Extensão. Trata-se de uma experiência que articula o ensino, a pesquisa e a extensão, através de projetos de intervenção envolvendo docentes e alunos de graduação de diferentes cursos. Essas disciplinas se diferenciam das demais pela liberdade na escolha de temáticas e na definição de sua metodologia (UFSCar, 2004). Diversas disciplinas ACIEPE já foram ofertadas desde a sua criação ${ }^{3}$ e o presente artigo trata do resultado das disciplinas que tiveram como foco central a recuperação e uso de documentos de patentes como fonte de informação.

A disciplina ACIEPE, com foco em patentes, é ofertada desde 2005 para todos os cursos de graduação da instituição. Primeiramente com a denominação Recuperação e Uso da Informação Patentária no Brasil, passando posteriormente a se chamar Patentes: Fonte de Informação Tecnológica (devido à dificuldade de entendimento pelo público-alvo do termo informação patentária), teve como objetivo oferecer um primeiro contato com a Lei de Propriedade Industrial, os conceitos básicos sobre patentes e proteção patentária e conhecimentos mínimos para a recuperação de informações em bases de dados nacionais e internacionais. Não teve como finalidade transformar o aluno em um perito em busca, e sim oferecer a ele a possibilidade de obter resultados razoáveis, e, ao mesmo tempo, condições mínimas para conversar com um especialista.

Foram ofertadas três turmas limitadas a um número máximo de 20 alunos por turma: a primeira teve a participação de alunos da Biblioteconomia e Ciência da Informação, Física, Engenharia Física, Engenharia de Produção e Engenharia de Materiais; na segunda participaram alunos de graduação dos cursos de Biblioteconomia e Ciência da Informação, Matemática, Psicologia,

3 Muitas disciplinas ACIEPE já foram ofertadas na UFSCar, tratando de diferentes assuntos e fazendo uso de recursos metodológicos diferenciados. Dentre elas temos comunicação, informação e meio ambiente; cooperativas populares e economia solidária; inclusão digital; música e ciências socias; pesquisa e extensão em agronomia; análise crítica da mídia: jornalismo, ciência e cultura; gestão de pequenas e médias empresas; rádio, televisão e outros meios de comunicação universitários; dentre outras (UFSCar, 2007). 
Engenharia de Produção e Engenharia Física; a terceira contou com alunos dos cursos de Biblioteconomia e Ciência da Informação, Física, Engenharia Física, Engenharia de Produção, Engenharia de Materiais, Matemática e Estatística. Como a UFSCar possui cursos em período integral (manhã e tarde), em período vespertino-noturno (tarde e noite) e em período noturno, foram agendados encontros semanais com todos os alunos da disciplina, entre o final do período da tarde e início do período noturno (entre $18 \mathrm{~h}$ e $19 \mathrm{~h}$ ).

Os tópicos tratados ao longo do semestre foram tipologia da informação, conceitos básicos de recuperação da informação, a Lei da Propriedade Industrial, o documento de patente, a padronização documental, a Classificação Internacional de Patentes, bases e bancos de dados, a recuperação da informação na base de dados do INPI e no Portal de Periódicos CAPES, além de outros temas relacionados à Propriedade Intelectual (direito autoral, direitos conexos, indicações geográficas, desenho industrial, cultivares e conhecimento tradicional).

Para alcançar o objetivo proposto, foram seguidos os seguintes passos metodológicos:

a) levantamento e revisão da literatura de referência sobre informação tecnológica, informação para negócios e recuperação da informação;

b) seleção e avaliação de fontes de informação sobre patentes;

c) exame da padronização documental, Classificação Internacional de Patentes e Codificação INID (Internationally Agreed Numbers for the Identification of Data);

d) recuperação da informação patentária contida na base de patentes do INPI e em outras bases de dados (Derwent Innovations Index, Esp@cenet, Intellectual Property Digital Library, United State Patent and Trademark Office) acessadas via Portal de Periódicos CAPES, dentre outras formas de acesso.

A carga horária foi de 60 horas-aula por disciplina (cada hora-aula corresponde a 50 minutos de atividades) e a avaliação do aprendizado se deu em três momentos distintos, através da análise dos relatórios de atividades dos grupos de trabalho. 
Com o objetivo de verificar o grau de interesse do aluno no tema, nenhuma atividade de divulgação foi concebida para "atrair" alunos para a disciplina. Ela foi ofertada juntamente com as demais disciplinas ACIEPE propostas por outros docentes da instituição, que trataram de diversos assuntos, dentre eles: o uso da literatura infantil para melhorar o ensino de matemática; educação de adultos; a gestão da informação; dentre outros temas (UFSCar, 2007). Mesmo assim, com um número máximo planejado de 20 alunos por turma, na primeira oferta inscreveram-se e cursaram 18 alunos; na segunda, 19; na terceira, 33 alunos.

A primeira oferta da disciplina foi desenvolvida em sala de aula tradicional sem recursos de informática, com visitas previamente agendadas ao setor de acesso a bases de dados da Biblioteca Comunitária da UFSCar. Contou-se com a presença de palestrantes ligados à área jurídica, à Ciência da Informação (bibliotecários especializados em informação tecnológica) e à Engenharia de Produção, todos atuantes na área de Propriedade Intelectual.

Para facilitar o acesso à Internet, as disciplinas seguintes foram desenvolvidas em sala de aula informatizada com acesso ao Portal de Periódicos CAPES. Na terceira oferta, utilizou-se como ferramenta adicional o ambiente de aprendizagem virtual denominado Moodle, ${ }^{4}$ uma ferramenta de gestão de cursos criada para auxiliar o processo de ensino-aprendizagem a distância. Esse ambiente permitiu a utilização de recursos que facilitaram a troca de conhecimento entre os participantes, que, devido ao fato de serem provenientes de cursos ministrados em diferentes períodos, tinham muita dificuldade em agendar encontros presenciais para a troca de experiências. Dentre os recursos possíveis de serem utilizados nesse ambiente, destacaram-se o fórum de debates, o fórum de notícias, a lista de e-mails de todos os participantes, a agenda e o relatório de atividades semanais, dentre outras ferramentas.

As atividades propostas aos grupos sempre se iniciavam com a construção pelos próprios alunos de protótipos de produtos já conhecidos (carro, balanço, panela, dentre outros), utilizando-se massa de modelar e brinquedos de montar. Era dada total liberdade para que os alunos criassem novos produtos e propusessem modificações nos produtos já comercializados no

\footnotetext{
4 Moodle: Modular Object-Oriented Dynamic Learning Environment. Mais informações disponíveis em <http://www.moodle. ufscar.br>.
} 
mercado. Na sequiência, era solicitada a recuperação dos documentos de patentes relacionados a essas tecnologias. Para coletar as informaçōes na base de patentes do INPI, foram utilizadas as duas opções: a pesquisa básica e a pesquisa avançada. A pesquisa básica foi realizada por meio do número do processo ou por palavras, havendo a opção de utilizar todas as palavras, a expressão exata, qualquer uma das palavras ou a palavra aproximada nos seguintes campos: título, resumo, nome do depositante e nome do inventor. Já na pesquisa avançada, outros campos de busca puderam ser utilizados, dentre eles a classificação, a data de depósito, o país da prioridade. Na pesquisa por título, resumo, nome do depositante e nome do inventor, foi possível utilizar a pesquisa booleana (and, or e not), pesquisa por palavras-chave, por frase exata e por proximidade entre palavras (INPI, 2007). Vale notar que todas as mudanças propostas pelos alunos em produtos conhecidos já haviam sido patenteadas.

Além da base de patentes do INPI, os alunos tiveram a oportunidade de experimentar recursos disponíveis no Portal de Periódicos CAPES (2007), que oferece textos completos de artigos de mais de 11.419 revistas nacionais e internacionais e mais de 90 bases de dados com resumos de documentos em todas as áreas do conhecimento. Em particular, foi possível a utilização da base de dados de patentes Derwent Innovation Index, mas priorizou-se o aprendizado na base BRASPAT do INPI, motivado, dentre outros fatores, pelo acesso gratuito, pelo conteúdo explicativo sobre a utilização da base e pelo idioma utilizado (português).

\section{Avaliação dos resultados}

Ao término de cada semestre, foram coletadas informações sobre o grau de satisfação do aluno com relação à temática apresentada e à metodologia utilizada, através de questionário contendo nove questôes fechadas e uma questão aberta, sem a identificação obrigatória do respondente. A amostra obtida totalizou 66 alunos, que representam 94,3\% dos questionários entregues.

Nessa amostra, a maior parte dos alunos provém do curso de Biblioteconomia e Ciência da Informação (59,1\%); em seguida das Engenharias $(19,7 \%)$ e dos cursos de Matemática, Estatística e Física (13,7\%), e 6,1\% dos 
alunos não se identificaram. Como nenhuma ação de divulgação da oferta da disciplina foi prevista, o que explica a motivação dos alunos do curso de Biblioteconomia e Ciência da Informação (BCI) a se inscreverem na disciplina foi o fato de ela ser ofertada pelo departamento responsável pelo curso de BCI. Os demais alunos foram informados da oferta por colegas e pelo site da instituição. Com relação ao ano de ingresso na instituição, os alunos que cursavam o primeiro ano do curso correspondiam a $18,2 \%$ da amostra; $15,2 \%$ cursavam o segundo ano; $37,9 \%$, o terceiro; $16,7 \%$ cursavam o quarto ano do curso e $12 \%$ não responderam.

O questionário foi aplicado na última semana de trabalhos da disciplina. Constituía-se de questões que envolviam temas relacionados à opção em cursar uma disciplina ACIEPE, ao conhecimento prévio sobre o assunto patentes, ao uso de documentos de patentes em trabalhos acadêmicos, dentre outras questôes. A questão aberta, que pedia sugestôes para a melhoria das práticas pedagógicas futuras, foi respondida por $42,4 \%$ dos alunos. Como resultado, tem-se:

a) Os motivos que levaram o aluno à escolha da disciplina e os aspectos da disciplina ACIEPE que mais chamaram sua atenção.

A possibilidade de adquirir conhecimentos sobre patentes $(62,1 \%)$, a possibilidade de aprimorar os conhecimentos que já possuía sobre patentes $(15,2 \%)$ e a possibilidade de cursar uma disciplina ACIEPE e adquirir novos conhecimentos $(13,6 \%)$ foram os motivos que levaram o aluno à escolha da disciplina (Gráfico 1). O tema patentes (Gráfico 2) aparece como o aspecto da disciplina ACIEPE que mais chamou a atenção do aluno (47\%), seguido de uma atividade interdisciplinar (24,3\%); uma disciplina que utiliza outros recursos metodológicos $(16,7 \%)$; da possibilidade de cursar uma disciplina que integra ensino, pesquisa e extensão $(12,1 \%)$. 
GRÁFICO 1

Motivo que levou o aluno à escolha da disciplina

(distribuição percentual)

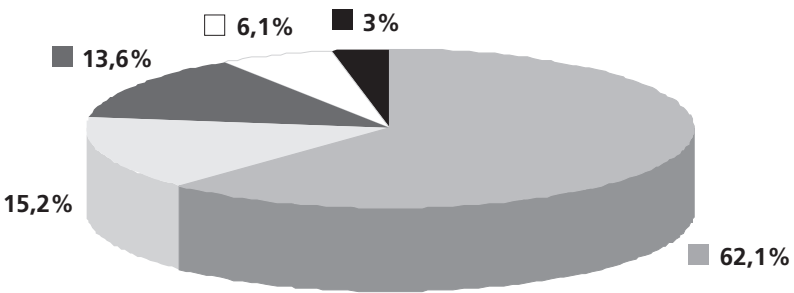

Possibilidade de adquirir conhecimentos sobre patentes

Possibilidade de aprimorar os conhecimentos que já possuía sobre patentes

Possibilidade de cursar uma disciplina ACIEPE e adquirir novos conhecimentos

Possibilidade de cursar uma disciplina ACIEPE

Outro

\section{GRÁFICO 2}

Aspecto da disciplina ACIEPE que mais chamou a atenção do aluno (distribuição percentual)

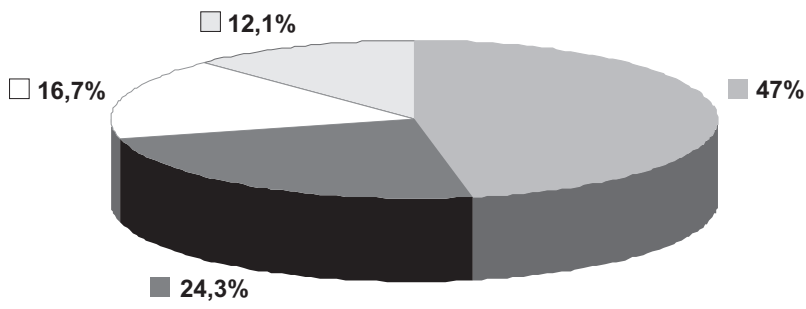

O tema patentes

Uma atividade interdisciplinar

Uma disciplina que utiliza outros recursos metodológicos

A possibilidade de cursar uma disciplina que integra ensino, pesquisa e extensão 
Destaca-se o interesse dos alunos pelo tema. Mas as características peculiares da disciplina ACIEPE (característica interdisciplinar/multidisciplinar, recursos metodológicos diferenciados, integração ensino/pesquisa/extensão) também aparecem como um atrativo.

b) Dificuldades encontradas para o entendimento do tema.

As maiores dificuldades (Gráfico 3) encontram-se no entendimento da legislação sobre patentes $(43,1 \%)$, da Codificação INID $(15,4 \%)$, da Classificação Internacional $(10,8 \%)$, dos procedimentos para recuperação de informações na base do INPI $(10,8 \%)$ e dos conceitos básicos sobre patentes $(1,6 \%)$. Observa-se que $18,5 \%$ não encontraram dificuldades no entendimento dos tópicos apresentados.

\section{GRÁFICO 3}

Tópico da disciplina considerado de maior grau de dificuldade (distribuição percentual)

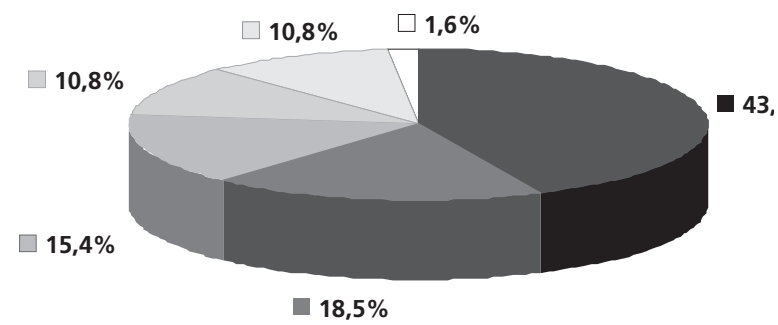

- Legislação

- Nenhum tópico

- Codificação INID

$\square \quad$ Classificação Internacional

Procedimentos para a recuperação da informação na base do INPI 
Para sanar os problemas encontrados no entendimento da lei n.9.279/96, foram convidados palestrantes da área jurídica que atuam em Propriedade Industrial. Mas vale lembrar que essa dificuldade encontrada pelos alunos é semelhante à encontrada por profissionais já formados, iniciantes no estudo do tema.

Apesar de poucos terem afirmado que o maior problema residiu na recuperação da informação $(10,8 \%)$, deve-se ressaltar que a questão se refere à recuperação da informação fazendo-se uso do mecanismo de busca simples. Quando era solicitada uma busca mais complexa, o resultado nem sempre era satisfatório.

c) Conhecimento prévio sobre o assunto.

Como apresentado no Gráfico 4, embora tenham declarado saber o que seja uma patente $(77,3 \%)$, a maioria dos alunos $(75,7 \%)$ nunca consultou um documento de patente (Gráfico 5) ou utilizou-o como referência em seus trabalhos acadêmicos $(92,4 \%)$, como mostra o Gráfico 6.

\section{GRÁFICO 4}

Distribuição percentual da resposta à questão:

Antes de se inscrever na disciplina, você sabia o que era uma patente?

\section{$22,7 \%$}

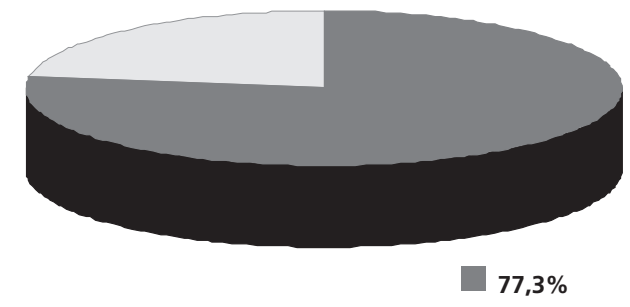

$\operatorname{sim}$

Não 


\section{GRÁFICO 5}

Distribuição percentual da resposta à questão:

Antes de se inscrever na disciplina, você já havia consultado um documento de patente?

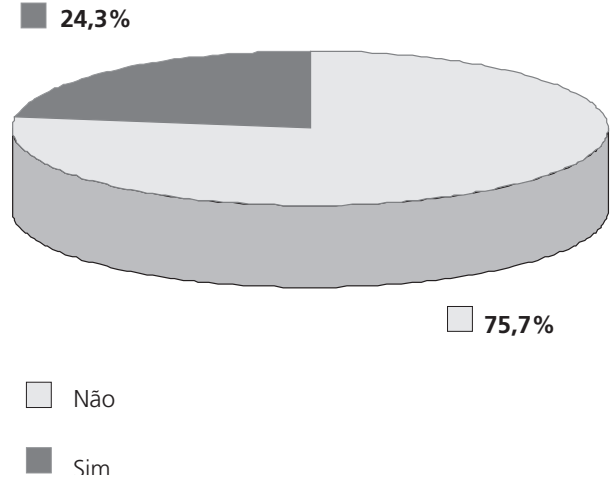

A não-utilização do documento de patente como referência nos trabalhos acadêmicos (Gráfico 6) alerta para a importância da inclusão desses documentos como fonte de informação nos cursos de graduação.

GRÁFICO 6

Distribuição percentual da resposta à questão:

Você já havia utilizado, como referência em seus trabalhos, um documento de patente?

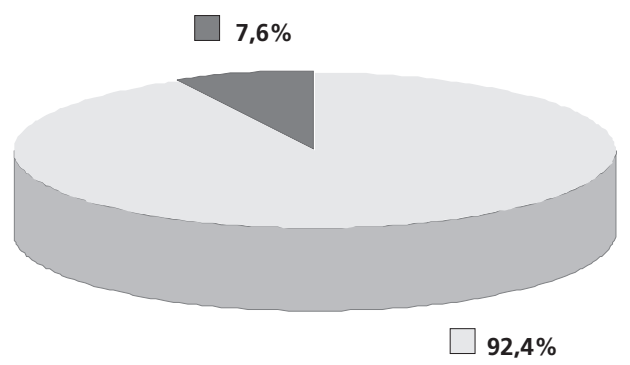

Não

$\operatorname{sim}$ 
O que justifica a maioria dos alunos ter afirmado saber o que é uma patente, apesar da não-utilização do documento de patente nas atividades acadêmicas anteriores, possivelmente se deve ao fato de alguns alunos possuírem conhecimento prévio adquirido através da consulta a outras fontes de informação, tais como jornais, revistas e páginas da Internet. Ao longo do curso, esse conhecimento se mostrou superficial e incorreto em alguns casos, levando a autora deste trabalho a preocupar-se com a qualidade da informação sobre Propriedade Intelectual oferecida pelos meios de comunicação de massa. Um estudo mais aprofundado sobre a qualidade dessas informaçōes será realizado após o mapeamento das principais fontes utilizadas pelos alunos, na próxima oferta da disciplina.

d) Como foram informados sobre a disciplina.

O aluno foi informado sobre a disciplina ACIEPE (Gráfico 7) através da página da UFSCar (47\%), de colegas $(37,9 \%)$ e da coordenação do curso que freqüenta $(6 \%)$.

\section{GRÁFICO 6}

Resposta à questão: Como você foi informado sobre a oferta da disciplina?

(distribuição percentual)

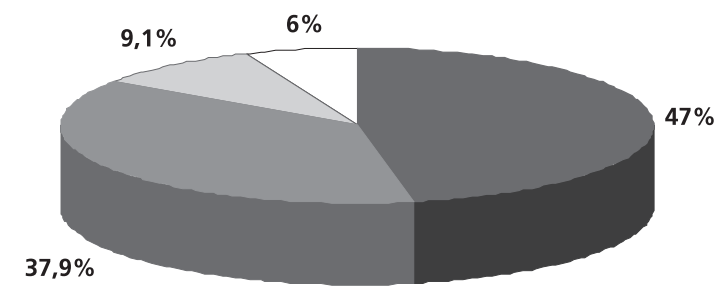

- Através da página da UFSCar

- Através de colegas

$\square$ Outra forma

$\square$ Através da Coordenação do seu curso 
Percebeu-se que, ao longo das três diferentes turmas, a informação sobre a oferta da disciplina, proveniente de colegas da universidade (Gráfico 8), cresceu consideravelmente. Na primeira turma, 3 alunos afirmaram que foram informados por colegas; na segunda turma, 7 alunos; na terceira turma, 15 alunos.

\section{GRÁFICO 8}

Número de alunos informados por colegas sobre a oferta da disciplina

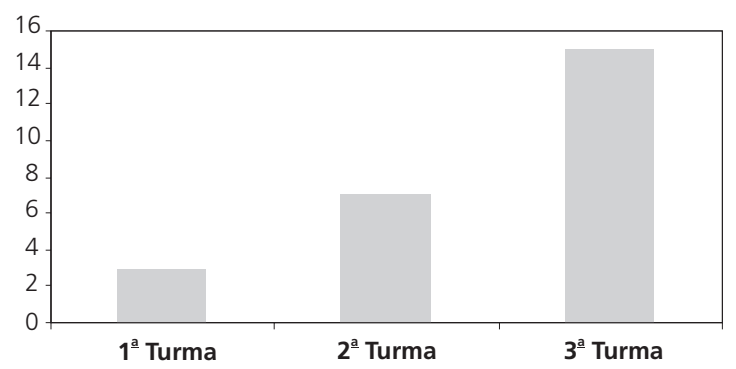

Pretendem aprimorar seus conhecimentos sobre o assunto (Gráfico 9), participando em outra disciplina sobre patentes $(37,9 \%)$; participando de cursos fora da UFSCar (25,8\%); estudando sozinho (24,3\%); estudando com colegas $(7,5 \%)$.

\section{GRÁFICO 9}

Formas de aprimorar o conhecimento sobre patentes (distribuição percentual)

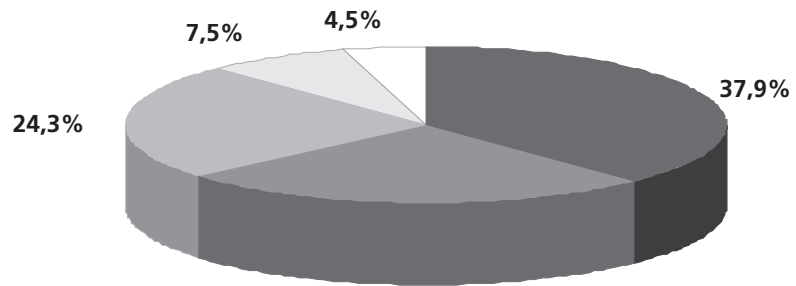

$25,8 \%$

Participando de outra disciplina sobre patentes

- Participando de cursos fora da UFSCar

Estudando sozinho

Estudando com colegas

Não gostaria de continuar os estudos sobre o tema patentes 
Somente $4,5 \%$ declararam que não gostariam de aprimorar seus conhecimentos sobre o assunto. Com relação aos $24,3 \%$ que manifestaram desejo de estudar sozinhos, muitos afirmaram que a idéia pareceu atraente porque não dispunham de tempo para a inclusão de mais uma disciplina em sua grade curricular. Essa iniciativa não foi recomendada, pois a disciplina tratou apenas de aspectos introdutórios, exigindo a continuidade dos estudos com orientação de profissionais da área.

\section{f) Outros aspectos destacados pelos alunos.}

- O trabalho em equipes multidisciplinares foi bem recebido por aqueles que conseguiram adequar seus horários com colegas de outros cursos; os alunos que não conseguiram (alunos de curso noturno que trabalhavam durante o dia, por exemplo) se queixaram por não terem essa oportunidade.

- O ambiente de aprendizagem Moodle mostrou-se um grande facilitador na comunicação entre todos os participantes (professor, alunos, monitor, palestrantes).

- Muitos encontraram dificuldades em acessar as bases internacionais e fazer uso da informação por não possuírem conhecimento suficiente da língua inglesa, principalmente do vocabulário técnico das áreas pesquisadas.

- As atividades lúdicas, que tinham como foco a disseminação da informação patentária, foram muito bem recebidas pela grande maioria dos alunos, pois, de acordo com eles, esse tipo de recurso metodológico criou um ambiente "leve", "mais harmonioso", estimulando a aproximação e interação entre todos.

\section{Conclusões e comentários finais}

O presente trabalho apresentou reflexões sobre o uso de documentos de patentes por alunos de graduação. Primeiramente trouxe, para a discussão do tema, os conceitos de informação, a informação tecnológica e a informação para negócios, além de apresentar a problemática da recuperação da informação sob os olhares da Ciência da Informação. Apresentou os objetivos, 
os tópicos abordados e os recursos metodológicos diferenciados utilizados pela disciplina ACIEPE com foco em patentes. Trouxe a análise, através da aplicação de questionário contendo perguntas fechadas e abertas, do resultado da oferta de 3 turmas, totalizando um universo de 70 alunos estudados, provenientes dos cursos de Biblioteconomia e Ciência da Informação, Física, Engenharia Física, Engenharia de Produção, Engenharia de Materiais, Matemática, Estatística e Psicologia.

Como conclusão tem-se que, ainda que o público envolvido nas atividades ACIEPE descritas anteriormente não represente o universo dos alunos de graduação do país, o resultado expõe de modo evidente a necessidade de se ampliar, no âmbito acadêmico, o debate sobre o sistema de Propriedade Intelectual. A concepção de disciplinas, com o formato da disciplina ACIE$\mathrm{PE}$, poderá trazer grandes benefícios para o estudo desse tema, pois permite a utilização de recursos metodológicos diferenciados e a interação entre alunos de diversas áreas em um ambiente que foge aos padrôes tradicionais de ensino-aprendizagem. Os resultados apontam também para a necessidade da inclusão, nas grades curriculares dos cursos de graduação, de disciplinas obrigatórias que tratem exclusivamente do tema Propriedade Intelectual.

Este trabalho, que é parte integrante do projeto de pesquisa Letramento em Propriedade Intelectual e Conhecimento Tradicional, pôde verificar que a metodologia utilizada para a construção da disciplina ACIEPE com foco em patentes é adequada e bem-aceita pelos alunos de graduação. $\mathrm{O}$ resultado dessa atividade servirá como subsídio para a formulação de hipóteses, objetivos e indicadores de avaliação, que fundamentarão a execução das próximas fases do projeto que consistem, dentre outras ações, na coleta, organização, tratamento e disseminação de informaçoos referentes a práticas pedagógicas em Propriedade Intelectual realizadas em outras universidades brasileiras; na elaboração, execução e avaliação de Programas de Intervenção para letramento científico e tecnológico em Propriedade Intelectual e Conhecimento Tradicional.

A criação de espaços de discussão sobre o uso da informação patentária, aliado ao emprego desse tipo de informação como referência nos trabalhos acadêmicos dos diversos cursos de graduação, permitirá que os alunos troquem experiências e aprendam a lidar com tão importante tema, antes de serem 
exigidos pelo mercado de trabalho que os espera. Espera-se que este trabalho contribua para despertar o interesse dos alunos pela temática e incentive outros docentes a desenvolverem atividades de capacitação em Propriedade Intelectual, voltadas a alunos de graduação.

\section{Referências bibliográficas}

Aguiar, A.C. "Informação e atividades de desenvolvimento científico, tecnológico e industrial: tipologia proposta com base em análise funcional", Ciência da Informação, Brasília, v.20, n.1, p.7-15, jan./jun., 1991.

Antunes, A.M.S.; Giannini R.G.; Borschiver, S.; Pereira V.L.S.B. "Tendências tecnológicas de polietilenos e polipropileno através da prospecção em documentos de patente nos Estados Unidos e Europa - 1990/1997”, Polímeros: Ciência e Tecnologia, v.10, n.1, p.56-63, 2000.

Barbosa, A.L.F. Sobre a propriedade do trabalho intelectual: uma perspectiva critica, Rio de Janeiro: Editora UFRJ, 1999.

Boccato, V.R.C.; Fujita, M.S.L. "Estudos de avaliação quantitativa e qualitativa de linguagens documentárias: uma síntese bibliográfica", Perspectivas em Ciência da Informação, Belo Horizonte, v.11, n.2, p.267-281, maio/ago., 2006.

Brandão, W.C. "A Internet como fonte de informações para negócio: um ensaio sobre a realidade da Internet brasileira", Perspectivas em Ciência da Informação, Belo Horizonte, v.9, n.1, p.88-99, jan./jun., 2003.

Branski, R.M. "Recuperação de informações na web", Perspectivas em Ciência da Informação, Belo Horizonte, v.9, n.1, p.70-87, jan./jun., 2004.

Cunha, M.B. Para saber mais: fontes de informação em ciência e tecnologia, Brasília: Briquet de Lemos, 2001. 
Cysne, F.P. "Transferência de tecnologia e desenvolvimento", Ciência da Informação, Brasília, v.25, n.1, p.26-35, jan./abr., 1996.

Dias, M.M.K.; Ferraz, M.C.C. Marketing em Ciência e Tecnologia: conceitos e princípios básicos para ambientes informacionais acadêmicos e organizacionais, São Carlos: EdUFSCar, 2006.

Ferneda, E. "Recuperação da informação: análise sobre a contribuição da Ciência da Computação para a Ciência da Informação", Tese apresentada para a obtenção do título de doutor em Ciências da Comunicação, São Paulo, USP, 2003.

Ferraz, M.C.C. Patentes: conceitos e princípios básicos para a recuperação da informação, São Carlos: EdUFSCar, 2006.

FIESP - Federação das Indústrias do Estado de São Paulo. "Pesquisa sobre propriedade industrial", 2003. Disponível em <http://www.fiesp.com.br/download/ pesquisa/propriedade.pdf $>$. Acesso em 26 de fevereiro de 2005.

França, R.O. "Patente como fonte de informação tecnológica", Perspectivas em Ciência da Informação, Belo Horizonte, v.2, n.2, p.235-264, jul./dez., 1997.

Furnival, A.C. Os fundamentos da lógica aplicada à recuperação da informação, São Carlos: EdUFSCar, 2002.

Gracioso, L.S. "Avaliação da linguagem documentária DeCS na base de dados LILACS", Revista de Iniciação Científica da F.F.C., Marília, v.3, n.1, p.45-66, 2000.

Haase, H.; Araújo, E.C.; Dias, J. "Inovações vistas pelas patentes: exigências frente às novas funções das universidades", Revista Brasileira de Inovação, v.4, n.2, p.329-362, jul./dez., 2005.

INPI - Instituto Nacional da Propriedade Industrial. Disponível em <http://www. inpi.gov.br>. Acesso em 18 de maio de 2007.

Kaback, S.M. “Online patent information: Who needs indexing? We do, naturally!”, World Patent Information, v.14, n.3, p.198-199, ago., 1992.

Le Coadic, Y.-F. A Ciência da Informação, Brasília: Briquet de Lemos, 1996.

Lopes, I.L. "Uso das linguagens controlada e natural em bases de dados: revisão da literatura”, Ciência da Informação, Brasília, v.31, n.1, p.41-52, jan./abr., 2002a. 
Lopes, I.L. "Estratégia de busca na recuperação da informação: revisão da literatura", Ciência da Informação, Brasília, v.31, n.2, p.60-71, maio/ago., 2002b.

Macedo, M.F.G.; Barbosa, A.L.F. Patentes, pesquisa \& desenvolvimento: um manual de propriedade intelectual, Rio de Janeiro: Fiocruz, 2000.

McGee, J.; Prusak, L. Gerenciamento estratégico da informação: aumente a competitividade e eficiência de sua empresa utilizando a informação como uma ferramenta estratégica, Rio de Janeiro: Elsevier, 1994.

Montalli, K.M.L.; Campello, B.S. "Fontes de informação sobre companhias e produtos industriais: uma revisão da literatura”, Ciência da Informação, Brasília, v.26, n.3, p.321-326, set./dez., 1997.

Pinho, F.A.; Basso, H.C.; Ferraz, M.C.C. "A participação de profissionais da informação em grupos de pesquisa”, in Furnival, A.C.; Costa, L.S.F. (orgs.), Informação e conhecimento: aproximando áreas do saber, São Carlos: EdUFSCar, 2005.

Portal de Periódicos CAPES. Disponível em <www.periodicos.capes.gov.br>. Acesso em 20 de maio de 2007.

Prazeres, P.M. Dicionário de termos da qualidade, São Paulo: Atlas, 1996.

Rodrigues, A.O. "A nova lei de patentes, a indústria química e a universidade", Química Nova, v.21, n.2, p.228-242, 1998.

Rowley, J. A biblioteca eletrônica, Brasília: Briquet de Lemos, 2002.

Santos, W.L.P. "Letramento em química, educação planetária e inclusão social", Química Nova, v.29, n.3, p.611-620, 2006.

Santos, M.E.R.; Rossi, A.L. "Estímulo à criação e consolidação de núcleos de propriedade intelectual e transferência de tecnologia em instituições de ensino e pesquisa brasileiras: relatório final da etapa mapeamento das instituiçôes", 2002. Disponível em <http://www.redetec.org.br/repict/documentos/ Relatrio\%20Final\%20Projeto\%20Ncleos\%20Definitivo\%201.pdf>. Acesso em 16 de outubro de 2007.

Souza, R.F. "A classificação como interface da Internet", DataGramaZero - Revista de Ciência da Informação, v.1, n.2, abr., 2000. 
Strenger, I. Marcas e patentes: análise sucinta da lei n.9.279, de 14 de maio de 1996, Rio de Janeiro: Forense Universitária, 1996.

UFSCar - Universidade Federal de São Carlos. Catálogo de atividades curriculares de integração entre ensino, pesquisa e extensão, 2004.

Atividades Curriculares de Integração entre Ensino, Pesquisa e Extensão, 2007.

Wandscheer, C.B. Patentes e conhecimento tradicional, Curitiba: Juruá, 2004.

ENDEREÇOS PARA CORRESPONDENCIA:

Maria Cristina Comunian Ferraz-cristina@ufscar.br Universidade Federal de São Carlos - Campus São Carlos

Centro de Educação e Ciências Humanas

Departamento de Ciência da Informação

Rodovia Washington Luís, km 235 - SP-310

São Carlos (SP) CEP 13565-905 